\title{
Including mental health among the new sustainable development goals
}

\author{
The case is compelling
}

\author{
Graham Thornicroft professor ${ }^{1}$, Vikram Patel professor ${ }^{23}$
}

${ }^{1}$ Centre for Global Mental Health, King's College London, Institute of Psychiatry, London SE5 8AF, UK; ${ }^{2}$ Centre for Global Mental Health, London School of Hygiene and Tropical Medicine, London, UK; ${ }^{3}$ Centre for Chronic Conditions and Injuries, Public Health Foundation of India, Gurgaon, India

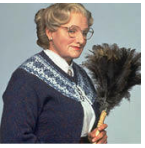

Him too

The United Nations will soon decide what will follow its millennium development goals, which expire in 2015. The case for including mental health among the new sustainable development goals is compelling, both because it cuts across most of the suggested new goals and because of the unmet needs of the 450 million people in the world with mental illness. ${ }^{1}$

Poorer mental health is a precursor to reduced resilience to conflict. It's also a barrier to achieving the suggested goal of promoting peaceful and inclusive societies for sustainable development, providing access to justice for all, and building effective, accountable, and inclusive institutions at all levels. In addition, conflict is itself a risk factor for adverse mental health consequences, ${ }^{2}$ and in the aftermath of conflict the needs of vulnerable groups such as people with mental illness are often accorded the lowest priority (as documented by photojournalist Robin Hammond, www.robinhammond.co.uk).

The improvement of mental health systems will also have a decisive role in making cities and human settlements inclusive, safe, resilient, and sustainable, and this is especially important given the global trend towards urbanisation with its associated risk factors for mental illness. Moreover, individual adversity-for example, complications of pregnancy, such as miscarriage - is associated with worse mental health.

A third suggested goal is to promote sustained, inclusive, and sustainable economic growth, full and productive employment, and decent work for all. People with mental illness have far lower rates of employment than the rest of the population, and periods of economic recession are related to worse mental health in the population, especially among men. ${ }^{3}$ More generally, people with untreated mental disorders have a negative effect on global wealth because they increase school and work absenteeism and dropout rates, healthcare spending, and unemployment rates. ${ }^{4}$ Disregarding the needs of the population for mental healthcare impairs productivity, ${ }^{5}$ costing the world in excess of $\$ 16$ tr (£9.5tr; $€ 12$ tr) a year in lost economic output. ${ }^{6}$

In order to ensure inclusive and equitable quality education and promote lifelong learning opportunities for all, we will have to recognise that mental health problems, especially developmental disorders such as attention-deficit/hyperactivity disorder, are often associated with educational underachievement and that these blight long term economic prospects. Moreover, educational stressors are risk factors for suicidality among school and college students. Mental health is also relevant to the goal of ending hunger, achieving food security, improving nutrition, and promoting sustainable agriculture. Mental illness in mothers is a risk factor for child undernutrition, ${ }^{7}$ and poor diet among people with severe mental illness contributes to their worse physical health. ${ }^{8}$

Ensuring healthy lives and promoting wellbeing for all at all ages is also impossible without a consideration of mental health. Inequality within and among countries cannot be fully addressed unless we recognise that nearly a quarter of the world population - the number who experience a mental illness each year-experience systematic discrimination in most areas of life. ${ }^{9}$ Indeed, the right to health, as incorporated in the United Nations Convention on the Rights of Persons with Disabilities, is manifestly neglected as the life expectancy among people with mental illness is up to 20 years lower among men and 15 years lower among women than among their counterparts without mental illness. ${ }^{10}$ People with severe infections (such as HIV/AIDS) or non-communicable diseases also show premature mortality if their adherence to medication is compromised by undetected or untreated coexisting mental illness. ${ }^{11}$ The fundamental point is that health must include mental health, as defined by WHO and accepted by all nations, not just in spirit but in reality. 
To turn to the arguments for directly meeting the needs of people with mental illness in the new development goals, the basic facts are clear and deeply disturbing. In high income countries about one quarter of people with mental illness receive care, and in low income countries fewer than one in ten do so. ${ }^{12}$ Two thirds of people with depression in the UK are not getting any treatment. ${ }^{13}$ By comparison, treatment rates for the main non-communicable diseases in low income countries commonly exceed $50 \% .{ }^{14}$ In other words, the mental health treatment gap is vast in all countries. ${ }^{15}$ Any approach to universal health coverage must therefore include the provision of treatment to people with mental illnesses. Together, these contribute to nearly a quarter of total years lived with disability across all conditions worldwide. ${ }^{16}$ At present, low income countries allocate about $0.5 \%$, and lower middle income countries $1.9 \%$, of their overall health budget to mental healthcare. ${ }^{17}$

The choice of sustainable development goals matters because national governments and international donors will give these the highest priorities for investment, as they did with the millennium development goals. We therefore call on the United Nations to include within the health related goal the following separate target: the provision of mental and physical health and social care services for people with mental disorders, in parity with resources for services addressing physical health. We also propose the inclusion of two key indicators identified in the WHO Mental Health Action Plan 2013-2020: service coverage for severe mental disorders will have increased by $20 \%$ by 2020 and the rate of suicide will be reduced by $10 \%$ by 2020 .

Competing interests: The authors have read and understood BMJ policy on declaration of interests and have no relevant interests to declare.

Provenance and peer review: Commissioned; not externally peer reviewed

1 WHO World Mental Health Survey Consortium. Prevalence, severity, and unmet need for treatment of mental disorders in the World Health Organization World Mental Health Survey. JAMA 2004:291:2581-90.

2 Kohrt BA, Hruschka DJ, Worthman CM, Kunz RD, Baldwin JL, Upadhaya N et al. Political violence and mental health in Nepal: prospective study. Br J Psychiatry 2012;201:268-75.

3 Katikireddi SV, Niedzwiedz CL, Popham F. Trends in population mental health before and after the 2008 recession: a repeat cross-sectional analysis of the 1991-2010 Health Surveys of England. BMJ Open 2012;2:e001790.

4 Collins PY, Patel V, Joestl SS, March D, Insel TR, Daar AS, et al. Grand challenges in global mental health. Nature 2011;475:27-30.
5 Kessler RC. The costs of depression. Psychiatr Clin North Am 2012;35:1-14.

World Economic Forum. The global economic burden of non-communicable diseases. World Economic Forum, 2011.

7 Surkan PJ, Kennedy CE, Hurley KM, Black MM. Maternal depression and early childhood growth in developing countries: systematic review and meta-analysis. Bull World Health Organ 2011;89:608-15.

8 McCreadie RG. Diet, smoking and cardiovascular risk in people with schizophrenia: descriptive study. Br J Psychiatry 2003;183:534-9.

9 Thornicroft G. Shunned: discrimination against people with mental illness. Oxford University Press, 2006.

10 Lawrence D, Hancock KJ, Kisely S. The gap in life expectancy from preventable physical illness in psychiatric patients in Western Australia: retrospective analysis of population based registers. BMJ 2013;346:f2539.

11 Mayston R, Kinyanda E, Chishinga N, Prince M, Patel V. Mental disorder and the outcome of HIV/AIDS in low-income and middle-income countries: a systematic review. AIDS 2012;26(suppl 2):S117-35

12 Wang PS, Aguilar-Gaxiola S, Alonso J, Angermeyer MC, Borges G, Bromet EJ, et al. Use of mental health services for anxiety, mood, and substance disorders in 17 countries in the WHO world mental health surveys. Lancet 2007;370:841-50.

13 McManus S, Meltzer H, Brugha T, Bebbington P, Jenkins R. Adult psychiatric morbidity in England, 2007: results of a household survey. NHS Information Centre for Health and Social Care, 2009

14 Ormel J, Petukhova M, Chatterji S, Guilar-Gaxiola S, Alonso J, Angermeyer MC, et al. Disability and treatment of specific mental and physical disorders across the world. $\mathrm{Br} \mathrm{J}$ Psychiatry 2008;192:368-75.

15 World Health Organization. mhGAP intervention quide for mental, neurological and substance use disorders in non-specialized health settings: mental health Gap Action Programme (mhGAP). WHO, 2010

16 Whiteford HA, Degenhardt L, Rehm J, Baxter AJ, Ferrari AJ, Erskine HE, et al. Global burden of disease attributable to mental and substance use disorders: findings from the Global Burden of Disease Study 2010. Lancet 2013;382:1575-86.

17 World Health Organization. WHO mental health atlas. WHO, 2011

18 UN General Assembly's Open Working Group proposes sustainable development goals. Press release, 22 July 2014. http://sustainabledevelopment.un.org/content/documents/ 4538pressowg13.pdf.

Cite this as: BMJ 2014;349:g5189

\section{Related links}

\section{thebmj.com/}

- News: Achieving millennium goals is crucial to global development beyond 2015, says UN chief (BMJ 2014;349: g4519)

- News: Strong government accountability is crucial to meeting millennium development goals, UN assembly is told (BMJ 2013;347:f5823)

- Analysis: What should follow the millennium development goals? (BMJ 2013;346:f1193)

(c) BMJ Publishing Group Ltd 2014 


\section{Proposed UN sustainable development goals ${ }^{18}$}

- End poverty in all its forms everywhere

- End hunger, achieve food security and improved nutrition, and promote sustainable agriculture

- Ensure healthy lives and promote wellbeing for all at all ages

- Ensure inclusive and equitable quality education and promote lifelong learning opportunities for all

- Achieve gender equality and empower all women and girls

- Ensure available and sustainable management of water and sanitation for all

- Ensure access to affordable, reliable, sustainable, and modern energy for all

- Promote sustained, inclusive, and sustainable economic growth, full and productive employment, and decent work for all

- Build resilient infrastructure, promote inclusive and sustainable industrialisation, and foster innovation

- Reduce inequality within and among countries

- Make cities and human settlements inclusive, safe, resilient, and sustainable

- Ensure sustainable consumption and production patterns

- Take urgent action to combat climate change and its impacts

- Conserve and sustainably use the oceans, seas, and marine resources for sustainable development

- Protect, restore, and promote sustainable use of terrestrial ecosystems, sustainably manage forests, combat desertification, and halt and reverse land degradation and halt biodiversity loss

- Promote peaceful and inclusive societies for sustainable development, provide access to justice for all and build effective, accountable, and inclusive institutions at all levels

- Strengthen the means of implementation and revitalise the global partnership for sustainable development 